\title{
Ten simple rules for implementing a flipped classroom
}

Pierre Poulain $\{1\}$, Mickael Bertrand $\{2\}$, Héloise Dufour $\{3,4\}$, Antoine Taly $\{5,6\}$

\{1\} Université de Paris, CNRS, Institut Jacques Monod, F-75006, Paris, France

\{2\} Éducation nationale, Académie de Dijon, Lycée Anna Judic de Semur-en-Auxois

\{3\} Cercle FSER, Paris, France

$\{4\}$ Inversons la Classe !, France

$\{5\}$ Laboratoire de Biochimie Theorique - CNRS, Universite de Paris, Sorbonne Paris Cite

$\{6\}$ Institut de Biologie Physico-Chimique, PSL University

\section{Abstract}

This manuscript aims to share some tips on implementing a flipped classroom, with examples from biology and computational biology. The proposed rules are:

- Invert time and Say It,

- Identify (or create) resources for learning at home,

- Be explicit on the acquisition of knowledge and engage students at home,

- Explore active learning in class,

- Develop skills of cooperation and sharing,

- Evaluate,

- Differentiate,

- Take care of the logistic and your posture,

- Document your flipped classroom,

- Share.

\section{Introduction}

This manuscript aims to share some tips on implementing a flipped classroom, with examples from biology and computational biology. The original idea of the flipped classroom is to reconsider the place of the work done at home and in class in order to reach a more effective learning experience (Schell \& Mazur, 2015). It is important to note that there are many practices that are associated with the generic term 'flipped classroom'. We will not detail here all the different forms, but we rather refer readers to comprehensive articles on the subject (Bishop \& Verleger, 2013; Lebrun \& Gilson, 2016). A question often raised is that of their effectiveness. On this subject we can formulate some preliminary remarks:

- It is difficult to make an overall assessment of flipped classrooms because this wording refers to many practices, very different from each other.

- Studies have shown positive effects of some protocols (Casasola et al., 2017; Crouch \& Mazur, 2001; Freeman et al., 2014), including the case of students facing difficulties (Lage et al., 2000). For the specific case of computational biology classes, Compeau published a detailed and positive feedback on this pedagogy (Compeau, 2019).

- A series of meta analysis identified by John Hattie (Visible Learning - Flipped Classrooms Details, 2020), suggests a significant efficiency of flipped classrooms (Chen et al., 2019; HEW \& LO, 2018; Karagöl \& Esen, 2019; Tan et al., 2017)).

- The research is far from over and several research articles call for more studies on this topic (Abeysekera \& Dawson, 2015; Bishop \& Verleger, 2013; Lo \& Hew, 2017).

\section{These 10 rules}

The rules presented below are inspired by the French national conference on flipped classrooms called CLIC, that takes place in Paris since 2015. They derived from the presentation of one of the authors (MB) at CLIC2018, augmented by the remarks of the audience during the presentation, recommendations of one of the references (Lo \& Hew, 2017) and re-analysed in our practitioner's point of view and from the perspective of the current literature. 


\section{Rule 1. Invert time and Say It}

The basic principle of flipped classroom invites considering the articulation of teaching and learning time (Schell \& Mazur, 2015). While school has long worked on a transmissive model, it was a question of no longer doing only a frontal course (Crouch \& Mazur, 2001). Importantly, knowledge transmission outside of the class is as efficient as inside the class room (DeLozier \& Rhodes, 2017).

The spread of the practice was accompanied by a reflection on the nature of the tasks self-directed by learners. It's not about giving more (Lo \& Hew, 2017), but to slide out of the classroom activities of lower cognitive level, and to perform in class tasks that require greater support from the teacher (Lebrun \& Gilson, 2016) (Table 1). With this model, the transmission of knowledge is done remotely, but its assimilation can be done face-to-face, via sessions of active pedagogy (Freeman et al., 2014). The inverted class then makes it possible to maximize the 'active' time in the classroom by moving the discovery of knowledge outside the classroom (DeLozier \& Rhodes, 2017).

When preparing a course, the teacher also needs to define activities that can support the acquisition of elements of knowledge by students in autonomy. For instance:

1. At the beginning of a course series, prerequisites can be reactivated or introductory concepts can be addressed.

2. Before a particular class, activity can prepare the learners to confront a complex task.

3. Along the course, the teacher can also provide learners a synthesis of the knowledge to be mobilized to answer a complex task;

4. At the end of a course series, students could work on a summary of the course.

Flipped classrooms modify how teaching is traditionally performed. Teachers need to explain the rules, for instance by providing detailed instructions in their syllabus. One way to enforce being explicit on what students are expected to do at home and in class is to clearly define pedagogical objectives also termed 'learning outcomes'. In designing pedagogical objectives for flipped classrooms, teachers have to keep in mind that activities performed at home by the students should be related to cognitive categories 'Remember', 'Understand' or 'Apply' (see Table 1).
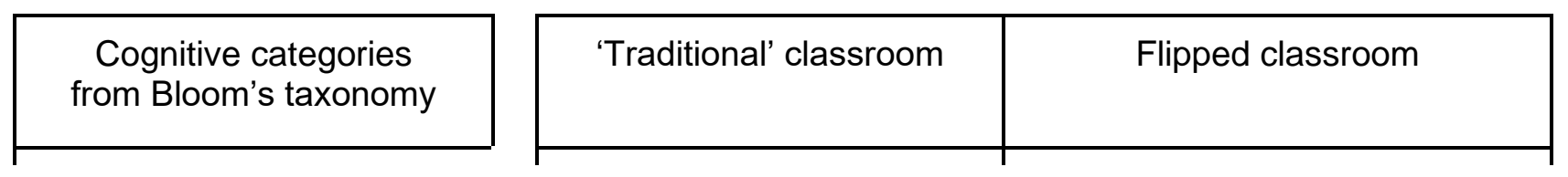

\begin{tabular}{|c|c|c|}
\hline Create & Evaluate & Analyse \\
\hline \multicolumn{3}{|c|}{ Apply } \\
\hline
\end{tabular}

Understand

\begin{tabular}{|c|c|}
\hline Home & University \\
\hline Home/University & Home/University \\
\hline University & Home \\
\hline University & Home \\
\hline
\end{tabular}

Table 1. The analysis of activities performed at home and at the university (right panel) are related with Bloom's taxonomy (left panel) (Anderson \& Krathwohl, 2001; Bloom, 1956; Sarawagi, 2014).

\section{Rule 2. Identify (or create) resources for learning at home}

Having some work to do at home means having something to read, to watch, or even to interact with. Most teachers will first try to generate their own media. This could be time consuming and sometimes discouraging, especially if the teacher aims to produce high quality video content steadily. We advocate for the reuse of resources openly available on-line or in the physical world. These can be textbooks, books, web-documentaries, handouts, video clips, MOOC excerpts, Wikipedia articles, etc ... The choice can be 
made according to students' needs and pedagogical objectives. Some selection criteria could be chapter or video length, presence of detailed plan, presence of companion exercises... However, after a careful assessment, the teacher will have to appropriate the selected material and, if needed, comment or expand it. In other terms, he/she will have to integrate this resource to her/his pedagogical mindset.

For video resources, a study (Guo et al., 2014) recommends choosing or creating short videos, 6 minutes or less, with a "Khan academy" style in which the teacher draws on the screen. Many detailed recommendations are available on this subject (Mayer \& Mayer, 2005). It should also be made clear that multiple resources are now freely available online, i.e. open education resources, whether they have been created by publishers or colleagues.

Whatever the chosen strategy, try to implement the change gradually (Lo \& Hew, 2017). Instead of creating something new from scratch, it is useful to use resources / protocols / lesson plans shared by others, i.e. start from something that worked elsewhere.

There are many ways to share resources with students. According to the context and material availability, teachers can share material:

- In a closed face-to-face system (for example, a handout distributed in class). No digital tool are required here.

- In a closed remote online system, for example with a learning management system (LMS) like Moodle, Blackboard, Canvas or with shared cloud drives.

- In a remote open system, e.g. a class blog or a website.

Regarding digital means to distribute teaching materials, some aspects need to be emphasized:

- It is crucial to ensure access to all students (Lo \& Hew, 2017). Students need to have the right equipment at home (internet connection, computer or tablet) or access to a library properly equipped.

- If sharing material through an open system is not imperative, it has several positive effects. Not only does it make available resources for other colleges and teachers, but it also provides a way to receive feedback from the community.

- It is also necessary to accompany learners for each new approach and tool used (Lo \& Hew, 2017).

\section{Rule 3. Be explicit on the acquisition of knowledge and engage students at home}

At the start of the semester it is advisable to be explicit about how the students will be working at home. In addition to clarify those aspects in the syllabus, it is useful to make a first session dedicated to the setup of the flipped classroom and during which students can be acquainted on the tools with the help from the teacher or teaching assistant (TA). Teachers also need to be patient during the first weeks, so that the students become confident about the method and the tools.

Before class, teachers must ensure that the resources made available have been consulted (Lo \& Hew, 2017). One has also to keep in mind that even if the activity performed at home is of relatively low cognitive level, support is usually required to limit the socio-academic inequalities associated with work done outside the class (Rayou, 2010).

Several types of activities can be considered to support the acquisition of knowledge:

- Take quizzes (possibly self-correcting) on the proposed material. Tools such as traditional LMS, Learning Apps, Educaplay, Education and Digital, Google Form, etc... could be used.

- Write down open questions on paper or through digital means.

- Participate in questions and answers sessions through LMS or messaging applications (Slack, Mattermost, Messenger...).

- Write a summary of the studied material. The produced summary can later be reviewed by peer students.

- List one thing the student found interesting and another one he/she wants clarifications on.

- Enrich collectively a course trail or share the results of a search on a collaborative writing document. Notwithstanding, this kind of activity is subject to limited support which must be followed by a class exchange session to make sure that the main elements are well acquired. 
The introduction of a flipped classroom is likely to be destabilizing or associated with misunderstandings about the objectives and / or above methods employed. It is therefore crucial to communicate effectively (Lo \& Hew, 2017) and to straighten rule \#1. Teachers need support from an efficient communication system (e-mails, social networks, LMS). A forum could allow students to ask questions whose answers can then be provided by the peers and / or the teacher before, during or even after class. It can also be useful to define an interaction protocol (who answers to who, and when). Office hours as implemented in the English-speaking world could be of great help toward this goal.

\section{Rule 4. Explore active learning in class}

One of the key idea of flipping a class is to make room for active learning during the lecture (DeLozier \& Rhodes, 2017). In active learning, students are involved and engaged with the course material into a large range of activities, such as discussions, quizzes, problem solving...

Active learning has been observed to improve students' achievements compared to traditional lecturebased teaching (Freeman et al., 2014) and some researchers suggest that the performance of flipped classrooms could actually be explained by the use of active learning (Jensen et al., 2015).

Many types of active learning strategies can be explored, from summarizing a book chapter to teaching part of the course (Fiorella \& Mayer, 2016). Among the activities that can be recommended in class, a recent review (DeLozier \& Rhodes, 2017) suggests: 1) testing outside and inside the class, with systems such as hands up, Plickers cards, clickers or any online voting systems (WooClap, Mentimeter, Kahout, Socrative...), 2) group discussions, 3) student presentations or teaching. More original methods can also be used like simulation games (Taly et al., 2018) or working side by side with students on research questions (Mazzanti et al., 2017). The time outside the class should not be left passive however, as any activity can be adapted in a more active manner (Chi \& Wylie, 2014).

In table 1, we highlighted the interest in analysing the tasks and activities students have to perform in their learning path. Most challenging tasks should be conducted in class with the guidance of the lecturer and through active learning. In the field of computational biology, a typical example of learning objectives difficult to reach via traditional lecturing but that strongly benefits from active learning is programming. Using more interactive material such as Jupyter notebooks (Le et al., 2020; Teaching and Learning with Jupyter, 2019) or the Rosalind auto-correcting exercise collection (Compeau \& Pevzner, 2018) are even more beneficial. Finally, it is possible to engage students working as teams on open research challenges (Abdollahi et al., 2018).

When it comes to choose a pedagogical approach, and latter when evaluating it (see rule \#6), it should be kept in mind that errors are acceptable. Many interactions could be necessary to obtain an acceptable pedagogical scenario (Compeau, 2019). In that regard, one interesting and encouraging observation is the 'teacher effect', i.e. that enthusiastic teachers have a positive effect just by trying (Hattie, 2008). We do interpret this observation as a right to tinker!

\section{Rule 5. Develop skills of cooperation and sharing}

A potential advantage of flipped classrooms is that they could develop cooperation skills (Strayer, 2012). It has also been observed that cooperation is an important parameter allowing the efficiency of a flipped classroom (Foldnes, 2016).

A typical example of activity that can be done in teams is the edition of wikipedia pages (Logan et al., 2010). In this perspective, many tools now have a "collaborative" mode to promote team production (Framapad, Prezi, Quizizz, Wiki, etc.). In the field of computational biology, it is also possible to share and document computer code (Abdollahi et al., 2018) with the help of version control systems and online collaborative development plateformes such as GitHub, Gitlab and others.

To the extent that it is an objective, it is appropriate to assess the nature of collaborative work (Lebrun \& Gilson, 2016). One way to do this is to involve peers in evaluation (Lopez et al., 2018).

\section{Rule 6. Evaluate}


In all cases, an assessment of the knowledge acquired during these preparatory activities is useful not only to ensure that activities have been seriously realized by the students, but also in order to make a diagnosis and bring targeted and immediate remediation with regard to statistical results. Voting systems such as Plickers, Quizizz, Woolcap, Kahoot, Socrative, etc. allow indeed to evaluate in class and just in a few minutes the knowledge acquired by the students.

Beyond the assessment of students and their learning, it is important to evaluate the devices / protocols used. This will naturally lead to the definition of performance indicators.

Among the success indicators for evaluating protocols (see Rule 5), it is interesting not to consider only grades, but also broader criteria such as absenteeism, conflict, autonomy, cooperation, etc.

The need for research being important (Abeysekera \& Dawson, 2015; Bishop \& Verleger, 2013; Lo \& Hew, 2017), studies conducted by teachers could provide a basis for participatory research.

\section{Rule 7. Differentiate}

Lo and Hew recommended individualized learning objectives (Lo \& Hew, 2017). Although flipped classrooms are not sufficient alone to perform differentiation, they facilitate its implementation enormously. Indeed, all of the active teaching activities listed above provide a record of student learning and progress (rule \#6). These information provided by these tools make possible diagnosis by question and by student, thus facilitating differentiation and remediation.

The flipped classroom requires being explicit (rule \#3), both in terms of material and guidelines provided. This also benefits students with special needs. Given that the transmissive part is studied individually by students it can in principle be proposed in more than one version, e.g. using different fonts or colour schemes.

\section{Rule 8. Take care of the logistic and your posture}

Engaging students to work on teaching material outside the classroom requires teachers to anticipate a broad, inclusive and seamless access to their material. Some technical solutions have already been provided above.

In class, material will be needed to allow group/team work such as paperboard, sticky notes, etc. In order to favor learning situations in teams, the need for a reorganization of the space within the class quickly becomes apparent. This arrangement aims to facilitate exchanges between students but also illustrates the change of posture of the teachers. Adoption of the flipped classroom approach is usually accompanied by reflection of the teacher on the layout of his classroom to allow him to no longer be in front of, or behind, his students, but close to, or even in the middle, of them. The teacher then shifts 'From sage on the stage to guide on the side' (King, 1993). This organization often results in the establishment of islands within which each team is invited to prepare an empty chair for the teacher to be then 'beside the students'

\section{Rule 9. Document your flipped classroom}

One advantage of a flipped classroom is to bring experiment and discovery back in the classroom. All these trial and errors need to be documented and written down, to keep tracks but also to allow a retrospective analysis of the pedagogical approach used.

We advise after each class to take a few minutes to write down what happened during the class, both positive and negative points, and highlight what could be improved in the next class. The students can be involved in that process. In our experience the adjustment proposed by students are often useful. Moreover, the process of consulting them goes in the direction of nurturing their intrinsic motivation (Oraif, 2018; Thai et al., 2017).

\section{Rule 10. Share}

As stated in the introduction, there is not one but many flipped classrooms. Yours will probably not be your colleague's flipped classroom. After one or more years, your experience will be valuable. Share it! 
You can publish your feedback as tweets, blog posts or even research articles. To foster sharing and exchange, we encourage the use of open licenses such as Creative Commons Attribution (CC-BY) or Creative Commons Attribution Share Alike (CC-BY-SA).

\section{Conclusion}

This article aims to gather some tips for implementing oneself flipped classrooms. In addition to changing the teacher's posture, the inverted class approach does change the atmosphere and working conditions for the teachers and the students.

Setting up a flipped classroom is often accompanied by an increased workload that could be reduced by adopting several strategies mentioned above: use of resources produced by others, automated corrections or peers assignments (Guilbault \& Viau-Guay, 2017)

One aspect highlighted above is the lack of research on flipped classrooms. It will therefore be important to enable participatory research on the subject to evaluate and document the multiple forms of flipped classrooms.

\section{Acknowledgments \\ CLIC2018 participants}

\section{References}

Abdollahi, N., Albani, A., Anthony, E., Baud, A., Cardon, M., Clerc, R., Czernecki, D., Conte, R., David, L., Delaune, A., Djerroud, S., Fourgoux, P., Guiglielmoni, N., Laurentie, J., Lehmann, N., Lochard, C., Montagne, R., Myrodia, V., Opuu, V., ... Lopes, A. (2018). Meet-U: Educating through research immersion. PLoS Computational Biology, 14(3).

https://doi.org/10.1371/journal.pcbi.1005992

Abeysekera, L., \& Dawson, P. (2015). Motivation and cognitive load in the flipped classroom: Definition, rationale and a call for research. Higher Education Research \& Development, 34(1), 1-14. https://doi.org/10.1080/07294360.2014.934336

Anderson, L. W., \& Krathwohl, D. R. (2001). A taxonomy for learning, teaching, and assessing: A revision of Bloom's taxonomy of educational objectives (Longman).

Bishop, J. L., \& Verleger, M. A. (2013). The flipped classroom: A survey of the research. ASEE National Conference Proceedings, 30, 1-18.

Bloom, B. S. (1956). Taxonomy of educational objectives. Vol. 1: Cognitive domain (pp. 20-24). McKay.

Casasola, T., Nguyen, T., Warschauer, M., \& Schenke, K. (2017). Can Flipping the Classroom Work? Evidence from Undergraduate Chemistry. International Journal of Teaching and Learning in Higher Education, 29(3), 421-435.

Chen, K.-S., Monrouxe, L., Lu, Y.-H., Jenq, C.-C., Chang, Y.-J., Chang, Y.-C., \& Chai, P. Y.-C. (2019). Academic outcomes of flipped classroom learning: A meta-analysis. Medical Education, 910- 
924. https://doi.org/10.1111/medu.13616@10.1111/(ISSN)1365-

2923.medical_education_in_review

Chi, M. T. H., \& Wylie, R. (2014). The ICAP Framework: Linking Cognitive Engagement to Active Learning Outcomes. Educational Psychologist, 49(4), 219-243.

https://doi.org/10.1080/00461520.2014.965823

Compeau, P. (2019). Establishing a computational biology flipped classroom. PLOS Computational Biology, 15(5), e1006764. https://doi.org/10.1371/journal.pcbi.1006764

Compeau, P., \& Pevzner, P. (2018). Bioinformatics Algorithms: An Active Learning Approach, 2nd Ed. Vol. (p. 5).

Crouch, C. H., \& Mazur, E. (2001). Peer Instruction: Ten years of experience and results. American Journal of Physics, 69(9), 970-977. https://doi.org/10.1119/1.1374249

DeLozier, S. J., \& Rhodes, M. G. (2017). Flipped Classrooms: A Review of Key Ideas and Recommendations for Practice. Educational Psychology Review, 29(1), 141-151. https://doi.org/10.1007/s10648-015-9356-9

Fiorella, L., \& Mayer, R. E. (2016). Eight Ways to Promote Generative Learning. Educational Psychology Review, 28(4), 717-741. https://doi.org/10.1007/s10648-015-9348-9

Foldnes, N. (2016). The flipped classroom and cooperative learning: Evidence from a randomised experiment. Active Learning in Higher Education, 17(1), 39-49. https://doi.org/10.1177/1469787415616726

Freeman, S., Eddy, S. L., Jordt, H., Smith, M. K., \& Wenderoth, M. P. (2014). Reply to Hora: Metaanalytic techniques are designed to accommodate variation in implementation. Proceedings of the National Academy of Sciences, 111(30), E3025-E3025.

https://doi.org/10.1073/pnas.1410405111

Guilbault, M., \& Viau-Guay, A. (2017). La classe inversée comme approche pédagogique en enseignement supérieur: État des connaissances scientifiques et recommandations. Revue internationale de pédagogie de l'enseignement supérieur, 33(33(1)).

http://journals.openedition.org/ripes/1193

Guo, P. J., Kim, J., \& Rubin, R. (2014). How video production affects student engagement: An empirical study of MOOC videos. Proceedings of the First ACM Conference on Learning @ Scale Conference, 41-50. https://doi.org/10.1145/2556325.2566239 
Hattie, J. (2008). Visible Learning for Teachers: Maximizing Impact on Learning. Routledge.

HEW, K. F., \& LO, C. K. (2018). Flipped classroom improves student learning in health professions education: A meta-analysis. BMC Medical Education, 18(1), 38. https://doi.org/10.1186/s12909018-1144-z

Jensen, J. L., Kummer, T. A., \& Godoy, P. D. d. M. (2015). Improvements from a Flipped Classroom May Simply Be the Fruits of Active Learning. CBE_Life Sciences Education, 14(1), ar5. https://doi.org/10.1187/cbe.14-08-0129

Karagöl, İ., \& Esen, E. (2019). The Effect of Flipped Learning Approach on Academic Achievement: A Meta-Analysis Study. Hacettepe Üniversitesi Eğitim Fakültesi Dergisi, 34(3), 708-727.

King, A. (1993). From Sage on the Stage to Guide on the Side. College Teaching, 41(1), 30-35. https://doi.org/10.1080/87567555.1993.9926781

Lage, M. J., Platt, G. J., \& Treglia, M. (2000). Inverting the Classroom: A Gateway to Creating an Inclusive Learning Environment. Journal of Economic Education, 31(1), 30-43.

Le, K., Adolf-Bryfogle, J., Klima, J., Lyskov, S., Labonte, J., Bertolani, S., Burman, S. R., Leaver-Fay, A., Weitzner, B., Maguire, J., Rangan, R., Adrianowycz, M., Alford, R., Adal, A., Nance, M., Das, R., Dunbrack, R., Schief, W., Kuhlman, B., ... Gray, J. (2020). PyRosetta Jupyter Notebooks Teach Biomolecular Structure Prediction and Design. https://doi.org/10.20944/preprints202002.0097.v1 Lebrun, M., \& Gilson, C. (2016). Vers une typologie des classes inversées. 22.

Lo, C. K., \& Hew, K. F. (2017). A critical review of flipped classroom challenges in K-12 education: Possible solutions and recommendations for future research. Research and Practice in Technology Enhanced Learning, 12(1), 4. https://doi.org/10.1186/s41039-016-0044-2

Logan, D. W., Sandal, M., Gardner, P. P., Manske, M., \& Bateman, A. (2010). Ten Simple Rules for Editing Wikipedia. PLOS Computational Biology, 6(9), e1000941. https://doi.org/10.1371/journal.pcbi.1000941

Lopez, H., Le Barch, K., Ethève-Quelquejeu, M., Pasquali, S., \& Taly, A. (2018). Poster Session with Peer Grading.

Mayer, R., \& Mayer, R. E. (2005). The Cambridge Handbook of Multimedia Learning. Cambridge University Press.

Mazzanti, L., Doutreligne, S., Gageat, C., Derreumaux, P., Taly, A., Baaden, M., \& Pasquali, S. (2017). What can human-guided simulations bring to RNA folding? Biophysical Journal, 113(2), 302- 
312.

Oraif, I. M. (2018). The University of Leicester. Leicester.

Rayou, P. (2010). Faire ses devoirs. Enjeux cognitifs et sociaux d'une pratique ordinaire. http://journals.openedition.org/lectures/2618

Sarawagi, N. (2014). A flipped CS0 classroom: Applying Bloom's taxonomy to algorithmic thinking. Journal of Computing Sciences in Colleges, 29(6), 21-28.

Schell, J., \& Mazur, E. (2015). Flipping the Chemistry Classroom with Peer Instruction. In Chemistry Education (pp. 319-344). John Wiley \& Sons, Ltd. https://doi.org/10.1002/9783527679300.ch13

Strayer, J. F. (2012). How learning in an inverted classroom influences cooperation, innovation and task orientation. Learning Environments Research, 15(2), 171-193. https://doi.org/10.1007/s10984012-9108-4

Taly, A., Nitti, F., Baaden, M., \& others. (2018). Molecular Modeling as the Spark for Active Learning Approaches for Interdisciplinary Biology Teaching.

Tan, C., Yue, W.-G., \& Fu, Y. (2017). Effectiveness of flipped classrooms in nursing education:

Systematic review and meta-analysis. Chinese Nursing Research, 4(4), 192-200. https://doi.org/10.1016/j.cnre.2017.10.006

Teaching and Learning with Jupyter. (2019). Retrieved July 1, 2020, from https://jupyter4edu.github.io/jupyter-edu-book/

Thai, N. T. T., De Wever, B., \& Valcke, M. (2017). The impact of a flipped classroom design on learning performance in higher education: Looking for the best "blend" of lectures and guiding questions with feedback. Computers \& Education, 107, 113-126.

https://doi.org/10.1016/j.compedu.2017.01.003

Visible Learning_Flipped classrooms Details. (2020). http://www.visiblelearningmetax.com/Influences/View/flipped_classrooms 